\title{
Container Slot Co-Allocation Planning with Joint Fleet Agreement in a Round Voyage for Liner Shipping
}

\author{
Jihong Chen ${ }^{1}$ and Shmuel Yahalom ${ }^{2}$ \\ ${ }^{1}$ (College of Transport and Communications, Shanghai Maritime University) \\ ${ }^{2}$ (State University of New York-Maritime College) \\ (E-mail: jhchen@shmtu.edu.cn)
}

\begin{abstract}
In the liner shipping market carriers share container slots to offer better service and realize economies of scale. This paper studies slot co-allocation planning for a joint fleet in a round trip for a shipping alliance in the liner shipping industry. In particular, a conceptual model is developed based on joint fleet and slot co-allocation management. The factors affecting slot co-allocation planning are explored in detail. A large-scale integer programming model is formulated to guide carriers in an alliance in pursuing an optimal slot co-allocation strategy. In contrast to the existing research, this approach leads to a more accurate representation of the situation for cooperative services in the liner shipping market. Extensive numerical experiments based on a true Asia-Europe cooperative route of COSCO and HANJIN show that the proposed model can be efficiently solved by LINGO11.0 for the case study. The computational results suggest that the mechanism and model can be used to benefit carriers in making better decisions in shipping cooperation services.
\end{abstract}

\section{KEY WORDS}

$\begin{array}{llll}\text { 1. Slot co-allocation. } & \text { 2. Joint fleet. } & \text { 3. Shipping alliance. } & \text { 4. Liner shipping. }\end{array}$

Submitted: 30 September 2012. Accepted: 2 April 2013.

1. INTRODUCTION. As world economic activities intensify, trade barriers fall, and the container liner shipping market globalizes, the formation of strategic alliances in the liner shipping industry has become common practice. By joining an alliance, shipping companies can share resources via slot purchase, slot exchange, and access to a joint fleet. It is vital to share container slots on a voyage, thereby improving equipment and terminal utilization. In a joint fleet operation, liner shipping alliances cooperate to offer cargo shipping and consolidation services to and from any part of the world. Slot co-allocation management for shipping alliances is still a key issue in the liner shipping industry. In many liner shipping companies, decisions on container slot co-allocation are made by employees with limited decision-support tools, making the alliance members' cooperation service often ineffective or unsuccessful. This study 
presents a conceptual model of joint fleet and slot co-allocation management for the liner shipping alliance members, providing carriers with an optimal solution.

2. LiteRATURE REVIEW AND OBJECTIVE. A number of research papers have focused on container shipping transportation and shipping alliances. Ding and Liang (2005) proposed the utilization of the fundamental principles encompassed in the fuzzy set theory to analyse and consider a multiplicity of complex criteria in order to determine the most suitable partner in a strategic shipping alliance. Dong and Song (2009) addressed the joint container fleet size and empty container repositioning in multi-vessel, multi-port and multi-voyage shipping systems under dynamic, uncertain and imbalanced customer demand conditions. Shahin, et al. (2010) proposed a mixed integer programming formulation for hub-and-spoke network design in a competitive environment, which addressed the competition between a newcomer liner service provider and an existing dominating operator, both operating on hub-and-spoke networks. Photis and Robert (2011) studied shipping alliance announcements that are related to operational and strategic changes, and developed an assessment relating them to the stability of collaborations.

Studies of slot allocation in the liner shipping industry have focused on different planning models and optimizations. Lu, et al. (2010a) addressed slot allocation planning of the container shipping firm in order to satisfy the estimated seasonal demand on a liner service, and explored in detail the influence of planning factors and constructed a quantitative model for the optimum allocation of a ship's slot space. Lu, et al. (2010b) studied slot exchange and purchase planning of short sea service for liner carriers and slot allocation planning for an alliance service with ship fleet sharing.

Agarwal and Ergun (2010) studied alliance formation among carriers in the liner shipping industry. They address tactical problems such as the design of large-scale networks and operational problems. More specifically, they address tactical problems with respect to the allocation of limited capacity among the carriers in the alliance and its impact on a transportation network. Zeng, et al. (2010) proposed a model to optimize the resource allocation for container lines. In their model they consider: ship size, container deployment, and slot allocation. The deterministic model that was initially developed was expanded to a robust optimization model incorporating uncertain factors. In this model, however, ship size was treated as the design variable and slot allocation as the control variable. Chen, et al. (2008a) offered a new model to analyse the issues of implementing route capacity cooperation and decision-making with respect to slot chartering allocation in the shipping alliance environment. Chen, et al. (2008b) established an optimization model for slot chartering allocation and route planning in a shipping alliance operation environment based on improving the traditional model for vessel allocation. Chen and Zhen (2010) proposed a nonlinear integer model for container slot exchange under shipping alliance operating regime. This model can help planners make better decisions under the alliance agreement and estimate shipping system costs more accurately, and is also pursued as an optimal scheduling strategy for shipping alliances.

Slot allocation optimization and management are closely linked to fleet deployment or planning as indicated by Wu (2009), Gelareh and Meng (2010), Meng and Wang (2010) and Shyshou, et al. (2010). Empty container repositioning was studied by Li, et al. (2004), Lam, et al. (2007) and Shintani, et al. (2007). Space allocation 
planning in container terminals was studied by Zhang, et al. (2003) and Bazzazi, et al. (2009). Some studies concentrated on the distribution of slot resources and their optimization under a regime of revenue or yield management for a single port pair. Ting (2004) offered a conceptual model for liner shipping revenue management, proposing a slot allocation model to maximize freight income. Feng and Chang (2008) also used revenue management modelling as a decision-support tool to enhance profit and management performance of liner shipping agencies. In other related industries, the slot allocation issue was also discussed by Madas and Zografos (2006), You (2008) and Zhang, et al. (2011); the models and optimization methods for slot allocation in other fields are similar to those in the shipping industry.

In the literature, there are few publications on the topic of shipping alliances' slot co-allocation. Most of the models that have been reported so far often consider only one company's shipping service with revenue management. However, in the liner shipping market, it is vital to consider shipping service cooperation and slot resource sharing for an alliance system at different demand situations for all the alliance members. Moreover, drawing inferences from similar research of liner shipping or shipping alliances, cooperation factors and different agreements should be included in creating a new optimization model. The new model proposed in this study provides a decision-making tool for slot co-allocation management, in a joint fleet operation or agreement environment. To achieve that cooperation target, each member of the operation that forms the joint fleet needs to keep all slots on the ship available for all alliance members for a round voyage. It is also noted that each member has different cargo prices, different cargo demands and different slot controlling strategies. On the basis of these facts, a new quantitative slot co-allocation model was developed that takes into account these cooperation conditions. In contrast to the existing models, this approach leads to a genuine representation of the operating situation given the special cooperation model of the liner shipping market. The optimization model can be used to decide on a sound slot allocating strategy for different types of containers shipped between different port pairs for different alliance members on a cooperative vessel in a round trip.

The purpose of this paper is to analyse relative factors of slot co-allocation planning for shipping alliance members in a cooperative environment with a joint fleet. The paper will propose a mathematical model for assigning slots to different types of containers that will comply with the requirements of all alliance members, which are based on demand for shipping services for multiple port pairs in a cooperative environment of a vessel round trip. A case analysis of the optimized model for an Asia-Europe cooperative shipping service is illustrated. The data for the case analysis is courtesy of the COSCO and HANJIN shipping companies.

3. PROBLEM DESCRIPTION. Containership slot management and allocation is very important since there is no revenue derived from unused space on board a vessel. Carriers must fill all the vessel space in a voyage in order to maximize revenue which in turn contributes to the voyage profit. In the face of fierce competition and an uncertain shipping market, liner carriers are advised to develop cooperative business models to avoid the risk of operating under-utilized vessels. Furthermore, even when space is fully utilized, companies could benefit from knowing the type of container combination that would maximize revenues. The objective could be 


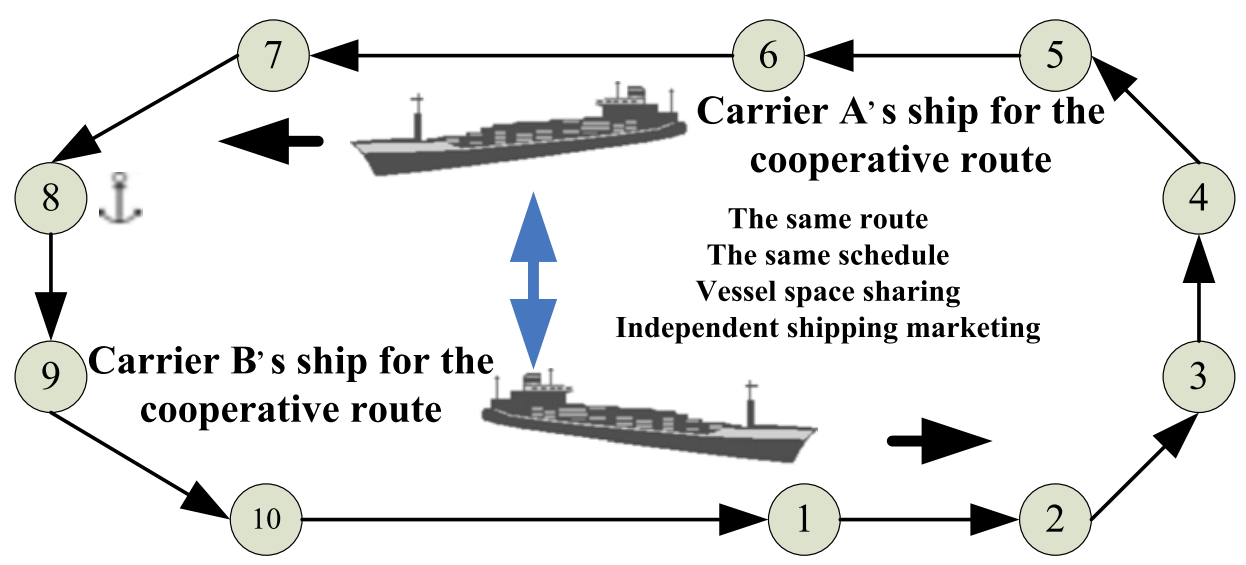

Cooperative route of carrier $A$ and $B$

Figure 1. Slot co-allocation in a round voyage and joint fleet.

achieved through cooperation of slot co-allocation and sharing ships' space. Thus, slot co-allocation with a joint fleet agreement is a special model for shipping alliance cooperation.

3.1 Slot co-allocation with a joint fleet. Slot co-allocation is defined in this paper as the cooperation of the shipping alliance members to assess the utilization of shared ship capacities in a round trip.

The cooperative model of a joint fleet, generally two or more ship operators, has an operating agreement for one or several shipping routes. In the agreement of liner service, frequency of port calls, shipping schedule, the number of ships offered by each alliance member and other issues are clearly defined. Cooperative entities are jointly responsible for operating the liner route, but the companies are independently responsible for marketing their own slot share in the voyage.

The main concept of slot co-allocation with joint a fleet agreement between the different parties of the alliance is illustrated in Figure 1 (Numbers 1 to 10 are calling ports). In this cooperative mode, in a round trip the ship operator is responsible for the seaworthiness and operation of the vessel. However, each partner is responsible for its own slot allocation. Each party independently and individually conducts marketing and documentation and is expected to maintain and continue all its commercial, operational and administrative activities in order to sustain and run its own business. For the cooperative route, each party offers a different number of ships. Each party receives the allotted slot space from the total slot space available in the voyage based on its contribution to the route slot space sale. Even though vessels are operated by different ship operators, for each round trip each party has the same schedule, calling ports, and share of space on board the ship.

3.2 Factors affecting slot co-allocation. As indicated before, slot utilization in the liner containership is vitally important; liner shipping companies try to avoid unused slots in a voyage to generate the highest possible revenue from containership slots. The main aspect of joint service in a joint fleet operating environment of slot co-allocation is subject to each party's slot cost, pricing, market demand, and type of container. 
In this study, slot cost is for a single container ship transport. This is a function of the variable cost of using the ship's space to transport a container. Shipping alliance members' slot costs are the driving factor for the optimization of slot co-allocation.

Pricing is one of the core elements of the shipping slot allocation system. In a fiercely competitive shipping market, freight rates cannot increase easily and must cover the costly repositioning of empty containers. Therefore, liner companies can have difficulty generating sufficient revenue and must optimize slot allocation and ensure their pricing and space utilization is as efficient as possible.

In the various market segments, different types of containers have their own freight rate. Obviously, carriers prefer to select containers with the highest return in order to increase their income. However, pricing is also influenced by market demand. To determine freight rates, carriers often engage in historical data analysis to forecast cargo demand, and adjust the prices with the evolving booking data from the agents or customers.

Carriers usually declare available space for slot allocation according to agents' space requests and demand for cargo. A Basic Slot Allocation table (BSA table) by country is often prepared for the local agents' freight services. However, the actual volume of container cargo a ship carries is limited by container and weight capacities. Therefore, space should be effectively allocated to maximize the freight, considering the market demand and the running ship's utilization.

Many different containers are used in liner shipping: 20-ft, 40-ft, refrigerated, and special containers. This variety makes slot co-allocation for alliance members very complex. For example, a $20-\mathrm{ft}$ container occupies a standard TEU (Twenty-foot Equivalent Unit) slot, and a 40 -ft container takes two standard TEU slots. A refrigerated container is restricted to space that includes electric outlets. Furthermore, each vessel has a specific number of slots for each container category of the 1 TEU, 2 TEU, etc. Even though there are no revenues generated from each member's own empty containers (there are revenues from the empty if the container belongs to another firm), empty container repositioning is an important and inevitable task because of the imbalance of import and export trade. Shipping companies move empty containers to support future voyages and to sustain the operation of the shipping service.

4. PLANNING MODEL FORMULATION. An optimization model for slot co-allocation in a round voyage of a joint fleet for a shipping alliance is now developed. More specifically, the focus is on optimization planning and the discovery of the deterministic parameters in order to maximize the total freight contribution to revenues from the complete voyage.

4.1 Model Assumptions. The model is subject to the following assumptions:

- The cooperative route in the model is an ocean liner trunk route. Thus, the slot co-allocation model ignores the impact on the regional transportation network.

- Under the joint service agreement the cooperative liner shipping route is known; therefore, the calling ports and port sequence of the route are determined in advance.

- In a round trip, there is only one ship running for all the alliance members. Total number of slots of each party for the voyage is determined in the agreement. 
- The freight rates and variable slot costs of each origin-destination port pair for the single voyage for a weekly shipping service have been estimated in advance for the round trip.

- The minimum/maximum container cargo demand of each origin-destination port pair for the local shipping agents or customers has been estimated based on the method identified above.

- The common types of containers and empty containers transported have been considered in the model. There are 12 major types of containers including laden and empty (i.e. 20' laden and empty dry container, 20' laden and empty reefer container, 20' laden and empty open top container, 40' laden and empty dry container, 40' laden and empty reefer container, 40' laden and empty open top container). A $20^{\prime}$ laden/empty container occupies one slot, and a $40^{\prime}$ laden/empty container occupies two slots.

4.2 Slot Co-Allocation Optimization Model. The purpose of slot resource sharing for the shipping alliance members is to maximize revenue generated. The shipping alliance business model indicates that each member of the alliance arranges for their own freight by container category. The model includes all served port pairs and origin-destination port pairs are chosen randomly from the pairs of ports available with the objective to maximize revenues.

The model's aim is to generate maximum revenue for the alliance members in the cooperative round trip while satisfying capacity, weight, demand and other constraints. It is formulated as follows (full notation is contained in the Appendix):

$$
\operatorname{Max} Z=\sum_{\forall i \in S A} \sum_{(o, d) \in \Omega} \sum_{k \in C T} w_{i}\left(F_{i o d}^{k}-C_{i o d}^{k}\right) X_{i o d}^{h k}
$$

such that,

$$
\begin{gathered}
\sum_{(o, d) \in \Omega} \sum_{k \in C O} a_{o d}^{s} t^{k} X_{i o d}^{h k} \leqslant U_{a i}^{h} \quad \forall s \in S, \forall i \in S A \\
\sum_{(o, d) \in \Omega} \sum_{k \in C O} a_{o d}^{s} w_{o d}^{k} X_{i o d}^{h k} \leqslant D W^{h} \quad \forall s \in S, \forall i \in S A \\
\sum_{(o, d) \in \Omega} \sum_{k \in R F} a_{o d}^{s} t^{k} X_{i o d}^{h k} \leqslant R P_{a i}^{h} \quad \forall s \in S, \forall i \in S A \\
D L_{i o d}^{k h} \leqslant X_{i o d}^{h k} \leqslant D U_{i o d}^{k h}, \quad \forall k \in C T, \forall(o, d) \in \Omega, \forall i \in S A \\
X_{i o d}^{h k} \geqslant E C_{i o d}^{k h} \quad \forall k \in E C, \forall(o, d) \in \Omega, \forall i \in S A \\
U_{a i}^{h}=\frac{\sum_{\forall h \in V S} N_{i}^{h} U_{i}^{h}}{\sum_{\forall h \in V S} N_{i}^{h} U_{i}^{h}+\sum_{\forall h \in V S} N_{j} U_{j}^{h}} \times U_{i}^{h} \quad \forall i, j \in S A, \quad i \neq j \\
R P_{a i}^{h}=\frac{\sum_{\forall h \in V S} N_{i}^{h} R P_{i}^{h}}{\sum_{\forall h \in V S} N_{i}^{h} R P_{i}^{h}+\sum_{\forall h \in V S} N_{j} R P_{j}^{h}} \times R P_{i}^{h} \quad \forall i, j \in S A, i \neq j \\
X_{i o d}^{h k} \in N \cup\{0\} \quad \forall k \in C O, \forall(o, d) \in \Omega, \forall i \in S A
\end{gathered}
$$


The objective of equation (1) is to maximize the total estimated revenues from various container categories for the alliance. In equation (1), the weight restriction is proposed as $\sum_{\forall i \in S A} w_{i}=1$. The shipping alliance business and agreement indicate that each member of the alliance can use slots on the ship; therefore, $w_{i}=\frac{1}{G}$ (where $\mathrm{G}$ is the number of shipping alliance members). Equations (2) and (3) are vessel capacity constraints. There are two major restrictions on the vessel capacity. Equation (2) implies that all the allocated slots for all kinds of laden and empty containers of all the alliance members cannot exceed the contractual capacities available (TEUs) for each member. Equation (3) ensures that the total weight of containers cannot exceed the vessel deadweight tonnage. Equation (4) indicates that all the slots for laden reefer containers cannot exceed the number of the vessel's reefer plugs. Equation (5) is cargo demand constraint for each alliance member; it provides the lower and upper bounds of allocated slots for laden containers of various categories and port pairs. Equation (6) is the empty container reposition demand constraint, which ensures that the total number of slots of empty containers must be greater than the reposition demand of ktype containers for each alliance member between different port pairs. Equations (7) and (8) are the constraints of the shipping alliance agreements for slot sharing under the joint fleet operation, which means that each member gets the slot capacity to use in a round trip according to his contribution to the route from the total capacity available to him. The integrity restrictions on the decision variables are represented in equation (9).

For a round trip, there is just one ship for the cooperative route; therefore, the number of variables in the model is the product of the number of shipping alliance members, the number of container categories and the number of port pairs. The model is a large scale integer programming (IP) model. This IP model can be solved by the traditional algorithm, such as the branch-and-bound method. For model solving, the optimization software LINGO11.0 can be utilized.

LINGO is a comprehensive optimization tool designed to make building and solving Linear, Nonlinear and Integer optimization models faster, easier and more efficient and can help cut development time. It formulates integer optimization problems quickly in a highly readable form. LINGO11.0 provides a completely integrated package that includes a powerful language for expressing optimization models, a full featured environment for building and editing problems, and a set of fast built-in solvers.

\section{MODEL APPLICATIONS AND RESULTS ANALYSIS. An} Asia-Europe cooperative service route with a joint fleet of two liner shipping companies COSCO and HANJIN (Figure 2) was used as a case study. These companies have been cooperating for a long time using different cooperation models. Slot sharing with joint fleets is an example of cooperation test.

5.1 Background for the Case Study. The tested cooperative route serves 8 ports in China, Hong Kong, Saudi Arabia, Germany, Britain and Belgium with 8 sailing legs. The port rotation is: XMN (Xiamen) - NSH (Nansha) - YTN (Yantian) - HKG (Hong Kong)-JED (Jeddah)-HAM (Hamburg)-FXT (Felixstowe)-ANR (Antwerp)-XMN (Xiamen). This loop is divided between East and West bounds (Figure 2). For the joint fleet in this cooperative route, the two companies deployed seven full-container vessels to provide weekly service for every calling port. 
Table 1. Weight and volume for different kinds of containers (COSCO and HANJIN).

\begin{tabular}{|c|c|c|c|c|c|c|c|c|}
\hline $\begin{array}{l}\text { Category code } \\
\text { Container type }\end{array}$ & $\begin{array}{l}20 \mathrm{GP} \\
20^{\prime} \text { dry }\end{array}$ & $\begin{array}{l}40 \mathrm{GP} \\
40^{\prime} \text { dry }\end{array}$ & $\begin{array}{l}20 \mathrm{RF} \\
20^{\prime} \text { 'reefer }\end{array}$ & $\begin{array}{c}40 \mathrm{RF} \\
40 \text { 'reefer }\end{array}$ & $\begin{array}{c}20 \mathrm{OT} \\
20^{\prime} \text { open top }\end{array}$ & $\begin{array}{c}40 \mathrm{OT} \\
40^{\prime} \text { open top }\end{array}$ & $\begin{array}{c}20 \mathrm{EC} \\
20^{\prime} \text { empty }\end{array}$ & $\begin{array}{c}40 \mathrm{EC} \\
40^{\prime} \text { empty }\end{array}$ \\
\hline Weight (ton) & 17 & 23 & 17 & 23 & 17 & 23 & 2 & 4 \\
\hline $\begin{array}{l}\text { Volume } \\
t^{k}(\text { TEU) }\end{array}$ & 1 & 2 & 1 & 2 & 1 & 2 & 1 & 2 \\
\hline
\end{tabular}

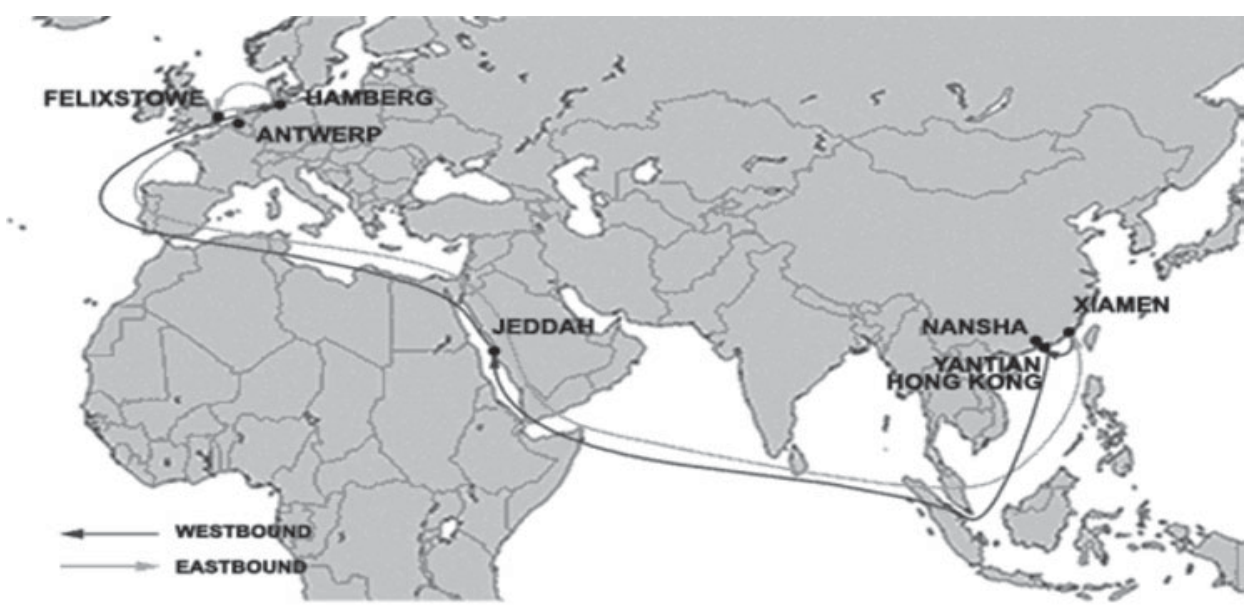

Figure 2. Cooperative service route with a joint fleet of COSCO and HANJIN vessels.

For a round trip, just one ship is used for slot co-allocation. According to alliance agreements and constraints equations (7) and (8) above, in a voyage, the two companies get their own slot space and reefer plugs for their container transport service. For this voyage, the available reserved space for the companies is 2,500 TEUs for COSCO, and 1,500 TEUs for HANJIN, respectively, without considering weight limitations. The maximum available deadweight tonnage for this voyage is 65,500 tons. The number of reefer plugs for COSCO is 300 and for HANJIN 100.

Besides the general types of containers, the two companies also accepted some special containers, such as $20-\mathrm{ft}$ and $40-\mathrm{ft}$ open top, and reefers. To simplify the problem, these out-of-gauge containers are a part of the special containers. Though the weights of loaded cargo in each type of container maybe different, for a realistic trip, shippers often load their cargoes into the container to a similar weight. Therefore, the similar value for each category as provided by the companies is used. Table 1 shows the container categories and their weights and volumes. For the case study and a cooperative route, a market-leg relation parameter, $a_{o d}^{s}$, with values of 1 or 0 is used. The values (of 1 and 0 ) are defined as whether the delivery passage was of port pair $(\mathrm{o}, \mathrm{d})$; passing the sailing leg $\mathrm{s}$ or not, 1 stands for yes and 0 stands for otherwise (Table 2). The analysis uses the two companies' weekly data of September 2009. Cost, revenue, number of ships in the joint fleet, dead weight tonnage, container demand and other databases variables are used to calculate the needed related model parameter data, such as: freight revenue, variable costs, container flow, and others. 
Table 2. Relationship between port pairs and legs $\left(a_{o d}^{s}\right)$ for the cooperative route.

\begin{tabular}{|c|c|c|c|c|c|c|c|c|c|c|c|c|c|c|c|c|c|}
\hline \multirow{2}{*}{$\begin{array}{l}\text { port } \\
\text { pairs }\end{array}$} & \multicolumn{8}{|c|}{ Sailing legs(s) } & \multirow{2}{*}{$\begin{array}{l}\text { port } \\
\text { pairs }\end{array}$} & \multicolumn{8}{|c|}{ Sailing legs(s) } \\
\hline & $1-2$ & $2-3$ & $3-4$ & $4-5$ & $5-6$ & $6-7$ & $7-8$ & $8-1$ & & $1-2$ & $2-3$ & $3-4$ & $4-5$ & $5-6$ & $6-7$ & $7-8$ & $8-1$ \\
\hline $1-2$ & 1 & 0 & 0 & 0 & 0 & 0 & 0 & 0 & $5-6$ & 0 & 0 & 0 & 0 & 1 & 0 & 0 & 0 \\
\hline $1-3$ & 1 & 1 & 0 & 0 & 0 & 0 & 0 & 0 & $5-7$ & 0 & 0 & 0 & 0 & 1 & 1 & 0 & 0 \\
\hline $1-4$ & 1 & 1 & 1 & 0 & 0 & 0 & 0 & 0 & $5-8$ & 0 & 0 & 0 & 0 & 1 & 1 & 1 & 0 \\
\hline $1-5$ & 1 & 1 & 1 & 1 & 0 & 0 & 0 & 0 & $5-1$ & 0 & 0 & 0 & 0 & 1 & 1 & 1 & 1 \\
\hline $1-6$ & 1 & 1 & 1 & 1 & 1 & 0 & 0 & 0 & $5-2$ & 1 & 0 & 0 & 0 & 1 & 1 & 1 & 1 \\
\hline $1-7$ & 1 & 1 & 1 & 1 & 1 & 1 & 0 & 0 & $5-3$ & 1 & 1 & 0 & 0 & 1 & 1 & 1 & 1 \\
\hline $1-8$ & 1 & 1 & 1 & 1 & 1 & 1 & 1 & 0 & $5-4$ & 1 & 1 & 1 & 0 & 1 & 1 & 1 & 1 \\
\hline $2-3$ & 0 & 1 & 0 & 0 & 0 & 0 & 0 & 0 & $6-7$ & 0 & 0 & 0 & 0 & 0 & 1 & 0 & 0 \\
\hline $2-4$ & 0 & 1 & 1 & 0 & 0 & 0 & 0 & 0 & $6-8$ & 0 & 0 & 0 & 0 & 0 & 1 & 1 & 0 \\
\hline $2-5$ & 0 & 1 & 1 & 1 & 0 & 0 & 0 & 0 & $6-1$ & 0 & 0 & 0 & 0 & 0 & 1 & 1 & 1 \\
\hline $2-6$ & 0 & 1 & 1 & 1 & 1 & 0 & 0 & 0 & $6-2$ & 1 & 0 & 0 & 0 & 0 & 1 & 1 & 1 \\
\hline $2-7$ & 0 & 1 & 1 & 1 & 1 & 1 & 0 & 0 & $6-3$ & 1 & 1 & 0 & 0 & 0 & 1 & 1 & 1 \\
\hline $2-8$ & 0 & 1 & 1 & 1 & 1 & 1 & 1 & 0 & $6-4$ & 1 & 1 & 1 & 0 & 0 & 1 & 1 & 1 \\
\hline $2-1$ & 0 & 1 & 1 & 1 & 1 & 1 & 1 & 1 & $6-5$ & 1 & 1 & 1 & 1 & 0 & 1 & 1 & 1 \\
\hline $3-4$ & 0 & 0 & 1 & 0 & 0 & 0 & 0 & 0 & $7-8$ & 0 & 0 & 0 & 0 & 0 & 0 & 1 & 0 \\
\hline $3-5$ & 0 & 0 & 1 & 1 & 0 & 0 & 0 & 0 & $7-1$ & 0 & 0 & 0 & 0 & 0 & 0 & 1 & 1 \\
\hline $3-6$ & 0 & 0 & 1 & 1 & 1 & 0 & 0 & 0 & $7-2$ & 1 & 0 & 0 & 0 & 0 & 0 & 1 & 1 \\
\hline $3-7$ & 0 & 0 & 1 & 1 & 1 & 1 & 0 & 0 & $7-3$ & 1 & 1 & 0 & 0 & 0 & 0 & 1 & 1 \\
\hline $3-8$ & 0 & 0 & 1 & 1 & 1 & 1 & 1 & 0 & $7-4$ & 1 & 1 & 1 & 0 & 0 & 0 & 1 & 1 \\
\hline $3-1$ & 0 & 0 & 1 & 1 & 1 & 1 & 1 & 1 & $7-5$ & 1 & 1 & 1 & 1 & 0 & 0 & 1 & 1 \\
\hline $3-2$ & 1 & 0 & 1 & 1 & 1 & 1 & 1 & 1 & $7-6$ & 1 & 1 & 1 & 1 & 1 & 0 & 1 & 1 \\
\hline $4-5$ & 0 & 0 & 0 & 1 & 0 & 0 & 0 & 0 & $8-1$ & 0 & 0 & 0 & 0 & 0 & 0 & 0 & 1 \\
\hline 4-6 & 0 & 0 & 0 & 1 & 1 & 0 & 0 & 0 & $8-2$ & 1 & 0 & 0 & 0 & 0 & 0 & 0 & 1 \\
\hline $4-7$ & 0 & 0 & 0 & 1 & 1 & 1 & 0 & 0 & $8-3$ & 1 & 1 & 0 & 0 & 0 & 0 & 0 & 1 \\
\hline $4-8$ & 0 & 0 & 0 & 1 & 1 & 1 & 1 & 0 & $8-4$ & 1 & 1 & 1 & 0 & 0 & 0 & 0 & 1 \\
\hline $4-1$ & 0 & 0 & 0 & 1 & 1 & 1 & 1 & 1 & $8-5$ & 1 & 1 & 1 & 1 & 0 & 0 & 0 & 1 \\
\hline $4-2$ & 1 & 0 & 0 & 1 & 1 & 1 & 1 & 1 & $8-6$ & 1 & 1 & 1 & 1 & 1 & 0 & 0 & 1 \\
\hline $4-3$ & 1 & 1 & 0 & 1 & 1 & 1 & 1 & 1 & $8-7$ & 1 & 1 & 1 & 1 & 1 & 1 & 0 & 1 \\
\hline
\end{tabular}

Note: The number for the port pairs indicates: 1stands for XMN, 2 for NSN, 3 for YTN, 4 for HKG, 5 for JED, 6 for HAM, 7 for FXT, and 8 for ANR; for example, port pair $(1,2)$ means XMN- NSN.

5.2 Results Analysis and Discussion. LINGO11.0 was used to solve the mathematical optimization model. The results are reported in the corresponding tables. The optimization problem has 1,536 variables and 801 constraints. The optimal slot allocation results in TEU for all sailing legs of a round trip are shown in Table 3, and the number of box results is displayed in Table 4.

Tables 3 and 4 indicate that some voyage legs are very busy, such as YTN-HKG, HKG-JED, JED-HAM, ANR-XMN and HAM-FXT, whose slots occupied by laden and empty containers reach almost $100 \%$ of the allotted space for each alliance member. The above legs play important roles in container cargo transport for the cooperative route. The leg YTN-HKG is the only way to transit goods from China's mainland area at Hong Kong port, and empty containers from Europe to China. Saudi Arabia and other regions transit through HKG-JED and JED-HAM; they are important westbound legs in the route for laden containers from China, Hong Kong to the Middle East and Europe. ANR-XMN is mainly used for laden container transport from the Middle East to China and Hong Kong, and for empty container 
Table 3. Slot occupation for all sailing legs for each member (TEU units).

\begin{tabular}{lcrrrrrrrr}
\hline \multirow{2}{*}{ Members } & & Type & $1-2$ & \multicolumn{1}{c}{ Legs } \\
\cline { 3 - 9 } & \multicolumn{1}{c}{ COSCO } & \multicolumn{1}{c}{$3-4$} & $4-5$ & $5-6$ & $6-7$ & $7-8$ & $8-1$ \\
\hline \multirow{3}{*}{ HANJIN } & Laden & 1101 & 1306 & 1875 & 2140 & 2191 & 1770 & 1490 & 1297 \\
& Empty & 959 & 737 & 625 & 360 & 309 & 674 & 933 & 1203 \\
& Laden & 284 & 515 & 769 & 1073 & 1130 & 702 & 260 & 93 \\
& Empty & 1121 & 864 & 731 & 427 & 370 & 798 & 1098 & 1407 \\
\hline
\end{tabular}

Table 4. Slot occupied results for all sailing legs for each member (number of boxes).

\begin{tabular}{|c|c|c|c|c|c|c|c|c|c|c|}
\hline \multirow[b]{2}{*}{ Members } & \multirow[b]{2}{*}{ Type } & \multirow[b]{2}{*}{ Container category } & \multicolumn{8}{|c|}{ Legs } \\
\hline & & & $1-2$ & $2-3$ & $3-4$ & $4-5$ & $5-6$ & $6-7$ & $7-8$ & $8-1$ \\
\hline \multirow[t]{12}{*}{ COSCO } & \multirow[t]{6}{*}{ Laden } & 20GP & 107 & 194 & 340 & 440 & 502 & 450 & 125 & 60 \\
\hline & & 40GP & 76 & 124 & 175 & 316 & 213 & 151 & 212 & 167 \\
\hline & & $20 \mathrm{RF}$ & 38 & 96 & 224 & 192 & 183 & 157 & 138 & 182 \\
\hline & & $40 \mathrm{RF}$ & 16 & 32 & 76 & 88 & 117 & 97 & 81 & 46 \\
\hline & & $20 \mathrm{OT}$ & 586 & 530 & 647 & 572 & 666 & 475 & 431 & 415 \\
\hline & & $40 \mathrm{OT}$ & 93 & 87 & 81 & 64 & 90 & 96 & 105 & 107 \\
\hline & \multirow[t]{6}{*}{ Empty } & 20GP & 287 & 222 & 191 & 115 & 101 & 206 & 281 & 359 \\
\hline & & 40GP & 216 & 166 & 143 & 85 & 73 & 154 & 211 & 271 \\
\hline & & $20 \mathrm{RF}$ & 95 & 73 & 63 & 38 & 33 & 68 & 93 & 119 \\
\hline & & $40 \mathrm{RF}$ & 26 & 18 & 13 & 4 & 3 & 15 & 24 & 34 \\
\hline & & $20 \mathrm{OT}$ & 67 & 54 & 45 & 27 & 23 & 48 & 65 & 83 \\
\hline & & $40 \mathrm{OT}$ & 13 & 10 & 7 & 1 & 0 & 7 & 12 & 16 \\
\hline \multirow[t]{12}{*}{ HANJIN } & \multirow[t]{6}{*}{ Laden } & 20GP & 76 & 123 & 241 & 403 & 557 & 371 & 65 & 33 \\
\hline & & 40GP & 39 & 62 & 83 & 181 & 83 & 58 & 34 & 16 \\
\hline & & $20 \mathrm{RF}$ & 34 & 54 & 88 & 79 & 77 & 53 & 33 & 14 \\
\hline & & $40 \mathrm{RF}$ & 4 & 12 & 12 & 21 & 23 & 17 & 0 & 0 \\
\hline & & $20 \mathrm{OT}$ & 72 & 138 & 162 & 137 & 168 & 52 & 46 & 14 \\
\hline & & $40 \mathrm{OT}$ & 8 & 26 & 44 & 25 & 58 & 38 & 24 & 0 \\
\hline & \multirow[t]{6}{*}{ Empty } & 20GP & 459 & 358 & 308 & 186 & 164 & 332 & 450 & 572 \\
\hline & & 40GP & 198 & 152 & 130 & 78 & 67 & 142 & 194 & 248 \\
\hline & & $20 \mathrm{RF}$ & 173 & 135 & 116 & 70 & 62 & 125 & 170 & 216 \\
\hline & & $40 \mathrm{RF}$ & 25 & 18 & 13 & 6 & 5 & 17 & 25 & 33 \\
\hline & & $20 \mathrm{OT}$ & 17 & 11 & 7 & 1 & 0 & 9 & 16 & 23 \\
\hline & & $40 \mathrm{OT}$ & 13 & 10 & 7 & 1 & 0 & 7 & 12 & 17 \\
\hline
\end{tabular}

repositioning from Europe to the Middle East, Hong Kong, and China. XMN-NSH and NSN-YTN are in China's mainland; their loading rates do not reach $100 \%$ and their space is mainly shared by empty containers. These two legs transit laden containers at Hong Kong from Xiamen and Nansha Ports and empty containers from Middle East and Europe to China's mainland.

In the cooperative route environment, slot allocation at the ports is critical for each alliance member in the joint fleet. The slot distribution between port pairs, the allocated results for different ports and the alliance members are summarized in Tables 5 and 6 . The allocated number of slots and TEUs of the main 12 types of containers are reported in the two tables. The optimum slot allocation in Tables 5 
Table 5. Number of boxes allocated for each member at the ports in the cooperative route.

\begin{tabular}{|c|c|c|c|c|c|c|c|c|c|c|c|c|c|}
\hline \multirow[b]{2}{*}{ Type } & \multirow[b]{2}{*}{ Port } & \multicolumn{6}{|c|}{ COSCO } & \multicolumn{6}{|c|}{ HANJIN } \\
\hline & & 20GP & 40GP & $20 \mathrm{RF}$ & $40 \mathrm{RF}$ & $20 \mathrm{OT}$ & $40 \mathrm{OT}$ & $20 \mathrm{GP}$ & 40GP & $20 \mathrm{RF}$ & $40 \mathrm{RF}$ & $20 \mathrm{OT}$ & $40 \mathrm{OT}$ \\
\hline \multirow[t]{8}{*}{ Laden } & XMN & 48 & 46 & 18 & 10 & 326 & 18 & 43 & 23 & 20 & 4 & 72 & 8 \\
\hline & NSH & 87 & 48 & 58 & 16 & 219 & 26 & 47 & 23 & 20 & 8 & 66 & 18 \\
\hline & YTN & 146 & 51 & 128 & 44 & 90 & 25 & 118 & 21 & 34 & 0 & 24 & 18 \\
\hline & HKG & 236 & 175 & 78 & 31 & 54 & 17 & 286 & 113 & 18 & 9 & 13 & 10 \\
\hline & JED & 297 & 52 & 114 & 63 & 249 & 55 & 441 & 15 & 13 & 7 & 77 & 58 \\
\hline & HAM & 32 & 11 & 5 & 2 & 159 & 36 & 10 & 5 & 4 & 0 & 0 & 0 \\
\hline & FXT & 10 & 144 & 93 & 24 & 154 & 34 & 7 & 4 & 4 & 0 & 14 & 0 \\
\hline & ANR & 13 & 9 & 79 & 18 & 102 & 35 & 11 & 5 & 4 & 0 & 0 & 0 \\
\hline \multirow[t]{8}{*}{ Empty } & $\mathrm{XMN}$ & 23 & 17 & 8 & 0 & 7 & 0 & 38 & 16 & 14 & 0 & 0 & 0 \\
\hline & NSH & 22 & 15 & 7 & 0 & 7 & 0 & 37 & 15 & 15 & 0 & 0 & 0 \\
\hline & YTN & 29 & 22 & 10 & 0 & 6 & 0 & 47 & 19 & 18 & 0 & 0 & 0 \\
\hline & $\mathrm{HKG}$ & 27 & 20 & 9 & 0 & 7 & 0 & 43 & 20 & 16 & 2 & 0 & 0 \\
\hline & JED & 29 & 22 & 10 & 3 & 6 & 0 & 48 & 19 & 19 & 3 & 0 & 0 \\
\hline & HAM & 125 & 94 & 41 & 12 & 29 & 7 & 199 & 87 & 74 & 12 & 9 & 7 \\
\hline & FXT & 97 & 72 & 32 & 9 & 22 & 5 & 153 & 66 & 57 & 9 & 7 & 5 \\
\hline & ANR & 97 & 72 & 32 & 10 & 22 & 5 & 153 & 66 & 57 & 9 & 7 & 5 \\
\hline
\end{tabular}

Table 6. Slot allocation results in TEU for each member at each port (TEU units).

\begin{tabular}{lccccccc}
\hline & \multicolumn{3}{c}{ COSCO } & & \multicolumn{3}{c}{ HANJIN } \\
\cline { 2 - 3 } Port & Laden & Empty & Total TEUs & & Laden & Empty & Total TEUs \\
\hline XMN & 540 & 72 & 612 & 205 & 84 & 289 \\
NSH & 544 & 66 & 610 & 231 & 82 & 313 \\
YTN & 604 & 89 & 693 & 254 & 103 & 357 \\
HKG & 814 & 83 & 897 & 581 & 103 & 684 \\
JED & 1000 & 95 & 1095 & 691 & 111 & 802 \\
HAM & 294 & 421 & 715 & & 24 & 494 & 518 \\
FXT & 661 & 323 & 984 & & 33 & 377 & 410 \\
ANR & 318 & 325 & 643 & & 25 & 377 & 402 \\
\hline
\end{tabular}

and 6 is different between ports. Due to the different marketing strategies of the two alliance members, the slot allocation of laden and empty containers for COSCO and HANJIN are different at the ports. COSCO's and HANJIN's slot numbers and TEUs for four ports (HKG, JED, HAM, and FXT) are larger than those for the other ports in the cooperative route, because these ports are important international transhipment ports or regional hubs.

The total slot allocation in TEU for each member at each port (Table 6) is the sum of the number of boxes allocated for each of the two members at each port (Table 5).

The slot allocation for the container categories provides revenue maximization, during a period of trade imbalance in the route. As shown in Tables 4 and 5, the results indicate:

- More slots are allocated for GP and OT containers, which contribute marginally more to the revenues per unit for the two members. 
- Empty containers do not provide benefits to the members. However, the demand for empty containers by the two members should be guaranteed for the next voyage.

- Both COSCO and HANJIN, due to trade imbalance (China's exports to Europe are more than China's imports from Europe), allocate laden slots for the westbound voyage, and empty slots for the eastbound voyage.

- This study of cooperative routes focused on multinational trade of goods.

In short, a few slots are arranged for laden containers within the region. The laden container cargo flow is mainly inter-regional, i.e., space for laden containers is mainly allocated for China, the Middle East and Europe inter-regional ports.

6. CONCLUSIONS. Traditionally, liner shipping companies focus on their own resources when offering sea cargo transport services. The liner shipping industry gained dramatically from the change in operation and business practice with shipping alliances. Shipping alliances allow carriers to realize the economies of scale and synergy in operation through different kinds of cooperation models. Slot co-allocation with joint fleets is one of the cooperative methods.

In this paper, liner shipping alliance and slot allocation are studied. The study provides an optimization solution to slot co-allocation with a joint fleet in a round trip based on shipping alliance member agreements. The optimization model is a largescale Integer Programming (IP) model. The results show the applicability and performance benefits (revenues and space allocation) of slot co-allocation planning. The slot co-allocation model outcome is consistent with the shipping alliance performance outcomes. This alliance model and example is a model for dealing with different alliance members' and their container cargo transport demand and revenue optimization.

\section{ACKNOWLEDGEMENTS}

This work is supported by the National Natural Science Foundation of China under Grants 71102043 and 71172076, and Shanghai Leading Academic Discipline Project (NO.S30601). The authors thank the two companies, COSCO and HANJIN, for providing basic data and practical knowledge regarding shipping alliance cooperation.

\section{REFERENCES}

Agarwal, R., and Ergun, O., (2010). Network design and allocation mechanisms for carrier alliances in liner shipping. Operation Research, 58(6), 1726-1742.

Bazzazi, M., Safaei, N., and Javadian, N., (2009). A genetic algorithm to solve the storage space allocation problem in a container terminal. Computers \& Industrial Engineering, 56(1), 44-52.

Chen, J. H., Zhen, H., and Zong, B. H., (2008a). Analysis of slot chartering \& allocation decision-making for containerized liner shipping under shipping alliance. Navigation of China, 31(4), 420-423.

Chen, J. H., Zhen, H., and Zong, B. H., (2008b). Improved vessel allocation model of liner shipping and its application for slot chartering under shipping alliance. Journal of Transportation Systems Engineering and Information Technology, 8(3), 120-125.

Chen, J. H., and Zhen, H., (2010). Planning \& decision-making model for liner shipping with container slot exchange under shipping alliance. Journal of Wuhan University of Technology (Transportation Science \& Engineering), 34(6), 1297-1301. 
Ding, J. F., and Liang, G. S., (2005). Using fuzzy MCDM to select partners of strategic alliances for liner shipping. Information Sciences, 173(1-3), 197-225.

Dong, J. X., and Song, D. P., (2009). Container fleet sizing and empty repositioning in liner shipping systems. Transportation Research Part E: Logistics and Transportation Review, 45(6), 860-877.

Feng, C. M., and Chang, C. H., (2008). Optimal slot allocation in intra-Asia service for liner shipping companies. Maritime Economics \& Logistics, 10(3), 295-309.

Gelareh, S., and Meng, Q., (2010). A novel modeling approach for the fleet deployment problem within a short-term planning horizon. Transportation Research Part E: Logistics and Transportation Review, 46(1), 76-89.

Lam, S. W., Lee, L. H., and Tang, L. C., (2007). Anapproximate dynamic programming approach for the empty container allocation problem. Transportation Research Part C: Emerging Technologies, 15(4), 265-277.

Li, J. A., Liu, A., Leung, S. C. H., and Lai, K. K., (2004). Empty container management in a port with longrun average criterion. Mathematical and Computer Modeling, 40(1-2), 85-100.

Lu, H. A., Chen, S. L., and Lai, P., (2010a). Slot exchange and purchase planning of short sea service for liner carriers. Journal of Marine Science and Technology, 18(5), 709-718.

Lu, H. A., Chu, C. W., and Che, P. Y., (2010b). Seasonal slot allocation planning for a container liner shipping service. Journal of Marine Science and Technology 18(1), 84-92.

Madas, M. A., and Zografos, K. G., (2006). Airport slot allocation: From instruments to strategies. Journal of Air Transport Management, 12(2), 53-62.

Meng, Q., and Wang, T. S., (2010). A chance constrained programming model for short-term liner ship fleet planning problems. Maritime Policy \& Management, 37(4), 329-346.

Photis, M.P., and Robert, W., (2011). Strategic alliances in container liner shipping. Research in Transportation Economics, 32(1), 25-38.

Shahin, G., Stefan, N., and David, P., (2010). Liner shipping hub network design in a competitive environment. Transportation Research Part E: Logistics and Transportation Review, 46(6), 991-1004.

Shintani, K., Imai, A., Nishimura, E., and Papadimitriou, S., (2007). The container shipping network design problem with empty container repositioning," Transportation Research Part E: Logistics and Transportation Review, 43(1), 39-59.

Shyshou, A., Gribkovskaia, I., and Barceló, J., (2010). A simulation study of the fleet sizing problem arising in offshore anchor handling operations. European Journal of Operational Research, 203(1), 230-240.

Ting, S. C., (2004). An optimal containership slot allocation for liner shipping revenue management. Maritime Policy \& Management 31(3), 199-211.

Wu, W. M., (2009). An approach for measuring the optimal fleet capacity: Evidence from the container shipping lines in Taiwan. International Journal of Production Economics, 122(1), 118-126.

You, P. S., (2008). An efficient computational approach for railway booking problems. European Journal of Operational Research, 185(2), 811-824.

Zeng, Q. C., Yang, Z.Z., and Chen, C., (2010). Robust optimization model for resource allocation of container shipping lines. Tsinghua Science \& Technology, 15(5), 586-594.

Zhang, C., Liu, J., Wan, Y.W., Murty, K. G., and Linn, R. J., (2003). Storage space allocation in container terminals. Transportation Research Part B: Methodological, 37(10), 883-903.

Zhang, W. Y., Zhang, S., Cai, M., and Huang, J. X., (2011). A new manufacturing resource allocation method for supply chain optimization using extended genetic algorithm. The International Journal of Advanced Manufacturing Technology, 53(9-12), 1247-1260. 


\section{APPENDIX}

The notation used in the model in this paper is as follows:

Indices:

$z=\quad$ Revenues of the shipping alliance system in the cooperative round voyage.

$i, j=\quad$ Index of different shipping alliance member, $i \neq j$.

$o, d=\quad$ Index of loading and discharging port, $(o, d)$ means origin-destination port pair.

$k=\quad$ Index of container type, including laden and empty ones. $k=20 \mathrm{GP}$ for $20^{\prime}$ dry container; $k=40 \mathrm{GP}$ for $40^{\prime}$ dry container; $k=20 \mathrm{RF}$ for $20^{\prime}$ reefer container; $k=40 \mathrm{RF}$ for $40^{\prime}$ reefer container; $k=20 \mathrm{OT}$ for $20^{\prime}$ open top container; $k=40 \mathrm{OT}$ for $40^{\prime}$ open top container, etc.

$s=\quad$ Segment or leg in the cooperative shipping route.

$h=\quad$ Ship type for the joint fleet in the cooperative shipping route.

Sets:

$S A=\quad$ Set of shipping alliance members, $\forall i, j \in S A, i \neq j$

$C O=\quad$ Set of all container categories, including laden and empty containers.

$\mathrm{CO}_{20}=$ Set of all $20 \mathrm{ft}$ container categories.

$\mathrm{CO}_{40}=$ Set of all $40 \mathrm{ft}$ container categories. Obviously, $\mathrm{CO}=\mathrm{CO}_{20} \cup \mathrm{CO}_{40}$.

$C T=\quad$ Set of all laden container categories.

$E C=\quad$ Set of all empty container categories. Obviously, $C O=C T \cup E C$.

$\Omega=\quad$ Set of all origin-destination port pairs of the cooperative route.

$S=\quad$ Set of all legs of the cooperative route.

$V S=\quad$ Set of all vessel categories of the joint fleet for the cooperative route.

Decision variables:

$X_{i o d}^{h k}=\quad$ Slot allocating number of k-type containers shipped between port pair $(o, d)$, on the cooperative vessel $h$ in a round voyage for alliance member $i$.

\section{Parameters:}

$a_{o d}^{s}=\quad$ An incident parameter to represent if the container delivery passage of

$t^{k}=\quad$ Number of slots occupied in TEU per container of category k. If $k \in C T_{20}$, port pair (o, d) passes legs, 1 for yes, 0 otherwise. $t^{k}=1$, if $k \in C T_{40}, t^{k}=2$.

$F_{i o d}^{k}=\quad$ Freight revenue of each k-type container delivered between port pair $(\mathrm{o}, \mathrm{d})$ for alliance member $\mathrm{i}$ in a cooperative round voyage. When $k \in E C$, $F_{\text {iod }}^{k}=0$.

$C_{i o d}^{k}=\quad$ Variable costs of each k-type container delivered between port pair $(\mathrm{o}, \mathrm{d})$ for alliance member $i$ in a cooperative round voyage.

$N_{i}^{h}=\quad$ Number of h-type vessel offered by alliance member i for joint fleet, $\forall i \in S A, \forall h \in V S$. Similarly, we know the meaning of $N_{j}^{h}$.

$U_{i}^{h}=\quad$ Total capacities in TEU for slot sharing of the deployed h-type ship offered by alliance member i, $\forall i \in S A, \forall h \in V S$. Similarly, we know the meaning of $U_{j}^{h}$.

$U a_{i}^{h}=\quad$ Available capacities in TEU of the deployed h-type ship for alliance member i, $\forall i \in S A, \forall h \in V S$. Similarly, we know the meaning of $U a_{j}^{h}$. 
$R P_{i}^{h}=\quad$ The maximum reefer plug number of the deployed h-type vessel from alliance member i, $\forall i \in S A, \forall h \in V S$. Similarly, we know the meaning of $R P_{j}^{h}$.

$R P a_{i}^{h}=\quad$ Available maximum reefer plug number for alliance member $\mathrm{i}$ on the deployed h-type vessel, $\forall i \in S A, \forall h \in V S$. Similarly, we know the meaning of $R P a_{j}^{h}$.

$D W_{k}=\quad$ The deadweight tonnage of deployed h-type vessel in the round voyage (unit: ton).

$w_{o d}^{k}=\quad$ Weight (tons) of each k-type container delivered between port pair (o, d).

$D L_{i o d}^{k h}=\quad$ The minimum contracted k-type container slot number of the agent between port pair $(\mathrm{o}, \mathrm{d})$ for alliance member $\mathrm{i}$, on the deployed h-type vessel in the cooperative voyage, when $\forall k \in C O$.

$D U_{i o d}^{k h}=\quad$ The maximum contracted k-type container slot number of the agent between port pair $(\mathrm{o}, \mathrm{d})$ for alliance member $\mathrm{i}$, on the deployed h-type vessel in the cooperative voyage, when $\forall k \in C O$.

$E C_{i o d}^{k h}=\quad$ The repositioning demand of k-type empty containers between port pair (o, d) for alliance member $\mathrm{i}$, on the deployed h-type vessel in the cooperative voyage, when $\forall k \in E C$. 